\title{
Block Chain Based Supply Chain Management for Counterfeit Drugs in Pharmaceutical Industry
}

\author{
Dr. Lokesh M R ${ }^{11}$, Suhail Ahmed M N ${ }^{2}$, Saifulla Khan ${ }^{3}$ \\ ${ }^{* 1}$ Professor, Department of Computer Science and Engineering Maharaja Institute of Technology, Mysore, \\ Karnataka, India \\ 2,3 UG Student, Department of Computer Science and Engineering Maharaja Institute of Technology Mysore, \\ Karnataka, India
}

\section{Article Info}

Volume 7, Issue 1

Page Number: 100-108

Publication Issue :

January-February-2021

\section{Article History}

Accepted : 17 Jan 2021

Published : 29 Jan 2021

\section{ABSTRACT}

This paper provides a detailed overview of the block chain technology and how it can be used to build a foolproof system in eliminating counterfeit products in pharmaceutical industries. From the last decade, pharmaceutical companies are facing difficulties in tracking their products during the supply chain process, allowing the counterfeiters to add their fake medicines into the market. Counterfeit drugs are analysed as a very big challenge for the pharmaceutical industry worldwide. As indicated by the statistics, yearly business loss of around $\$ 200$ billion is reported by US pharmaceutical companies due to these counterfeit drugs. These drugs may not help the patients to recover the disease but have many other dangerous side effects. According to the World Health Organization (WHO) survey report, in under-developed countries every 10th drug use by the consumers is counterfeit and has low quality. Hence, a system that can trace and track drug delivery at every phase is needed to solve the counterfeiting problem. The block chain has the full potential to handle and track the supply chain process very efficiently. In this paper, we have proposed and implemented a block chain based drug supply chain management. Our proposed system block chain-based drug supply chain management for consumers. In this drug supply chain management the system is deployed using Hyper ledger fabrics which is capable of continuously monitor and track the drug delivery process in the smart pharmaceutical industry. Finally, we also perform several tests to check the efficiency and usability of our proposed system.

Keywords: Block Chain, Drug Supply Chain, Anti - Counterfeit, Healthcare, Smart Contract, Hyper Ledger Fabrics

\section{INTRODUCTION}

The block chain has the full potential to handle and track the supply chain process very efficiently. In this paper, we have proposed and implementing block chain-based drug supply chain management for consumers. The drug supply chain management system is deployed using Hyper ledger fabrics, which is capable of continuously, monitor and track the

Copyright: (C) the author(s), publisher and licensee Technoscience Academy. This is an open-access article distributed under the terms of the Creative Commons Attribution Non-Commercial License, which permits unrestricted noncommercial use, distribution, and reproduction in any medium, provided the original work is properly cited 
drug delivery process in the smart pharmaceutical industry.

The exiting work were, assigning a dedicated individual or group in your organization to monitor the security of your supply chain. WHO Checklist (World Health Organization Tool for visual inspection).The purpose: Examination of packaging the disadvantages is Pharmacist or Healthcare provider required \& performance is low. There are few methods/techniques to overcome the counterfeit of drugs such as Visual Inspection the with respect to the product, packaging, and its labelling. The Disadvantage are not an automatic process. The Electronic Medical Records (EMR) the Disadvantage are Potential privacy \& Security concerns, Inaccurate Information, Malpractice Liability concerns. Supply chain management system (SCM) the enable companies to efficiently handle the flow of good from suppliers to customers. The Disadvantages are public block chain, Centralised System. According to the World Health Organization (WHO) survey report, in under- developed countries every 10th drug use by the consumers is counterfeit and has low quality. News about Made in India: 35\% of world's fake drugs claim one in five drugs sold in India is counterfeit, according to the Associated Chambers of Commerce and Industry of India (Assocham). Worldwide, 35\% of all fake drugs originate in India.

The important and primary goal of the block chain network is to store information in a distributed way where each block contains multiple transactions. These transactions are stored in an encrypted and hashed manner for security concerns. The proposed system is a service-oriented framework for the users, which provides the distributed ledger and smart contract functionalities as service. The proposed system is the drug supply chain management system, in this system, end-user (suppliers, distributors, pharmacy, doctors, manufacturer and patients) can perform the transaction by using the front-end web application where they can perform medicine orders, raw material supply, update the medicine data, update orders, update the records, deliver drugs, data sharing, track drug at every step of supply, drug management, customers management, etc. The first primary goal of this system is to prevent counterfeit drugs and provide a secure SCM system to the endusers. Our proposed system is secure because of block chain security and integrity management features.

\section{METHODS AND MATERIAL}

\section{a. Related Work}

As per a recent world annual report by a market research firm Evaluate Pharma, the pharma industry is set to witness a growth rate of 6.3\% CAGR globally through 2022 with a market cap of $\$ 1.2$ trillion. One of the biggest challenges in an industry this big is that of counterfeit products entering the consumer market. However, unlike in other industries, counterfeit products not only have a negative economic impact, but also a serious social impact as wrong/fake drugs can easily alter the course of treatment meted to the end consumer. Counterfeit products range from drugs with no active ingredients to those with dangerous levels of adulteration. They are usually copies of branded drugs, generic drugs or over-the-counter drugs.

The counterfeit drugs market is estimated to be worth anywhere between $\$ 75 \mathrm{~B}$ to $\$ 200 \mathrm{~B}$ a year and could add up to half the drugs in circulation in some low-income countries. A recent study conducted by the European Union Intellectual Property Office (EUIPO) notes that fake medicines results in an annual loss of over 37,000 jobs and cost the EU pharmaceutical sector in excess EUR 10.2 billion each year. This is only the tip of the iceberg, as the study does not include downstream counterfeit.

Counterfeiting groups usually originate and thrive in countries where the anti-counterfeiting and IP 
protection laws are weak and ineffective. Counterfeit drug has become a global phenomenon spread across higher-income countries such as in the US (reported 10 times more often within the last 5 years in the United States) and Europe (counterfeit products increased by $118 \%$ within 1 year (2007 to 2008). In developing countries, counterfeit drugs account for between $10 \%$ and $30 \%$ of all drugs sold.

In Data Handling \& Drug Traceability: Block chain Meets Healthcare To Combat Counterfeit Drugs [Kavita Kumari en., al.2020] authors have discussed the problems with traditional methods of data handling and drug traceability and how block chain overcomes those problems. Moreover, we have proposed a system, which is capable of tracing drugs in the supply chain, and reduce counterfeiting of drugs. The process for drug traceability system using block chain is represented. The manufacturer manufactures drugs and binds it with a unique hash code. The manufacturing details of the drugs along with the hash code are stored on the block chain. Next in the supply, chain comes the distributor.

The manufacturing details of the drugs along with the hash code are stored on the block chain. However, this method does not provide the distributed ledger system.

In Block chain Technology in Pharmaceutical Industry to Prevent Counterfeit Drugs [Ijazul Haq en., al. 2018] suggested that the production and distribution of counterfeit drugs is an urgent and increasingly critical worldwide issue, especially in developing countries. The market value of pharmaceutical counterfeiting has reached billions of dollars annually. One of the reasons for drugs counterfeiting is the imperfect supply chain system in pharmaceutical industry. When a factory produce a new product, they will create a unique hash and assign it to the product. The product will be registered on the block chain using its hash (unique ID). The product will be considered as a digital asset on the block chain network, and its hash will be used to track it any time on the network. Once the manufacturer registers the product to the block chain, its ownership will be easily transfer to another participant using a user-friendly mobile APP.

In CFDD ( Counter Feit Drug Detection) using Block chain in the Pharmaceutical Industry [Kavita Kumari en., al. 2019] counterfeit drugs is an expanding serious issue associated with the healthcare industry which causes extreme threats to the society. The traceability of the drugs throughout the pharma supply chain is a difficult task. Another serious issue in combating counterfeit medicines in healthcare systems is the maintenance and sharing of health records. Manufacturers drugs/medicines assigns a unique code, the information added to the block chain then the distributor verifies the origin of the drugs, the transaction is stored on the block chain. The pharmacist verifies the origin of the drugs then stores the transaction on the block chain. The patient also verifies the origin of the drugs.

In Traceability and detection of counterfeit medicine supply chain through Block chain [Ghodekar Prachi Shrikant en., al. 2019] suggests that design system for traceability and detection of fake medicine supply chain using block chain which provides traceability of drugs from manufacturer to end consumer and detection of manufacturing process of medicines to overcome drug safety issue. Manufacturing Medicines/Drugs and new transactions added to a block is immutable and time stamped which means that the information cannot be tampered with. Distributed ledger shared among the parties involved in the manufacturing and distribution of the drug.

In a Novel Medical Block chain Model for Drug Supply Chain Integrity Management in a Smart Hospital [Faisal Jamil en., al. 2019] at present, in pharmacology one of the most serious problems is counterfeit drugs. The Health Research Funding 
organization reported that in developing countries, nearly $10-30 \%$ of the drugs are fake. Counterfeiting is not the main issue itself, but, rather, the fact that, as compared to traditional drugs, these counterfeit drugs produce different side effects to human health, but the author used complex method to implement the model.

In a Novel approach for Traceability and detection of counterfeit medicines through Block chain [Ms.Kajal Bharat Adsul en., al. 2019] in existing supply chain gadget, data isn't always shared between systems, producers don $t$ know what happened to their products, pills regulatory authority has no visibility of the system, recalls are complex and costly, and corporations cannot follow-up patients The block chain is beneficial in keeping tune of the complete production chain of the drug. Each new transaction brought to a block is immutable and time stamped this means that that the information cannot be tampered with. On those block chains, the corporations may have an allotted ledger shared some of the events involved inside the manufacturing and distribution of the drug. Moreover, access is only limited depending on records sharing contract between the 2 parties.

In a Block chain-Based Application System for Product Anti-Counterfeiting [Jinhua Ma en., al. 2020] Block chain technology as the base architecture ensures that the contents of its data are tamper-proof. This paper uses the decentralized Block chain technology approach to ensure that consumers do not fully rely on the merchants to determine if products are genuine. Our product anti-counterfeiting system based on Block chain is composed of three roles, The Manufacturer Role, The Seller Role, and The Consumer role the proposed system uses Ethereum as the back end Block chain operating system and uses Ethereum's proprietary programming language Solidity as the high-level programming language for writing smart contracts. Solidity supports inheritance, libraries importing, etc. Solidity is designed for Ethereum Virtual Machine (EVM). Unlike Bitcoin's scripts, Solidity provides loops and it is Turing complete.

\section{b. Proposed System}

The decentralized distributed nature of block chain technology has extended the security and privacy of the drug supply chain of the pharmaceutical industry. The complete drug supply chain management is presented with participants, block chain network in in which users can manage, and updates the whole supply chain activities. The data related to the users of the system suppliers, manufacturer, distributors, pharmacies, hospitals, doctors and patients are stored in the block chain-based system. Each user of the system is provided with client application based front-end where they can easily perform their transaction and communicate with the block chain network.

In our system, the first supplier sends the raw material to the drug company. Each participant of the system has a web application portal where each user can login and perform the transaction. Suppose a manufacturer orders place for raw material, the supplier receives that order. Afterward, when the raw material order is ready to deliver then supplier performs the confirm order event. On the other hand, if a customer does a detailed check of a company's medicine data, only he/she can perform those actions, which are defined as permission rules in the block chain network. In another case, if a doctor wants to place an order to a medicine company then he/she can place the order using our proposed block chain system as the same steps defined in the above-mentioned scenario. Firstly, authentication of that doctor, submit the transaction proposal, manufacturers validate the transaction, then confirm the transaction of the doctor and notify 
the order status by sending event message successful transaction.

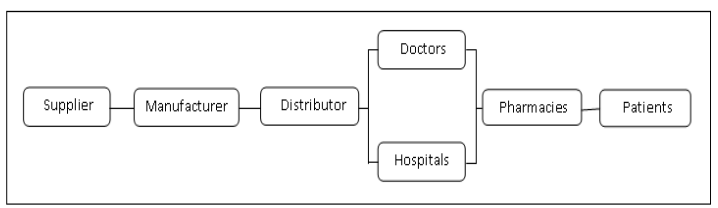

Figure 1: Drug Supply Chain Management

\section{c. Design Flow:}

The proposed system is a service-oriented framework for the users, which provides the distributed ledger and smart contract functionalities as service. The main design of the proposed system is shown in Figure 2. The proposed system is the drug supply chain management system. In this system, end-user (suppliers, distributors, pharmacy, doctors, manufacturer and patients) can perform the transaction by using the front-end web application where they can perform medicine orders, raw material supply, update the medicine data, update orders, update the records, deliver drugs, data sharing, track drug at every step of supply, drug management, customers management, etc. The first primary goal of this system is to prevent counterfeit drugs and provide a secure SCM system to the end-users.

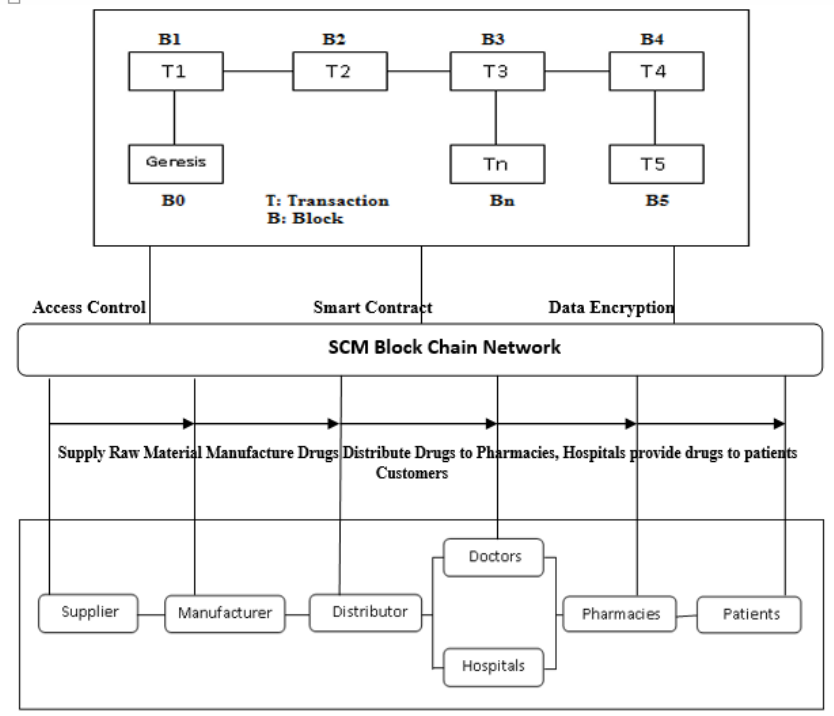

Figure 2 : Overview Of Drug Supply Chain Management With Block Chain

\section{d. Implementation}

The tools and technologies used for the implementation of the proposed system test-bed are presented in Table 2 with their required configurations. We build and deploy our proposed test-bed in two separate environments. For providing the users an attractive graphical user interface, we used front-end languages like HTML, CSS, JAVASCRIPT, JQUERY and a third party framework twitter bootstrap for developing client web-based application. The open-source hyper ledger Fabrics block chain technology is used for the deployment of this system, which requires docker engine, python, node JS and VS code as prerequisites. The Linux operating system Ubuntu 18.04 LTS is used for the deployment of the block chain network. The hyper ledger composer is utilized for building the business logic's of the proposed network where we have defined our participants, assets, access control rules and smart contracts. The client application is connected with the block chain business network through the composer REST server in which participants can visualize and performs all the activities at their own web-based portals. The user can generate HTTP requests using GET, POST, PUT, DELETE methods through and response will be provided through the block chain system accordingly.

\begin{tabular}{|c|c|}
\hline System Component & Description \\
\hline IDE (Platform) & Visual Studio \\
\hline CPU & $\begin{array}{c}\text { Intel (R) Core (TM) } \\
\text { i5-7400 CPU at 3.00 } \\
\text { GHz }\end{array}$ \\
\hline Hyperledger Fabric & v1.12 \\
\hline Docker Engine & Version 18.06.1-ce \\
\hline Docker Composer & Version 1.13. \\
\hline Primary Memory & 32 GB RAM \\
\hline CLI Tool & composer-cli, \\
& composer-rest- \\
& server, \\
\hline
\end{tabular}




\begin{tabular}{|c|c|}
\hline & $\begin{array}{c}\text { composer- } \\
\text { playground }\end{array}$ \\
\hline $\begin{array}{c}\text { Programming } \\
\text { Language }\end{array}$ & python, tensor-flow \\
\hline Client application & Solidity, Node JS, \\
& HTML, CSS, JS, \\
& Twitter Bootstrap, \\
& JQ angular JS \\
\hline Operating System & Ubuntu Linux \\
& 18.04 .1 LTS \\
\hline
\end{tabular}

Table 2: Tools and technologies for the implementation of the proposed system.

The hyper ledger composer is the best open-source option for the development of block chain-based applications. One of the major features of this network is to design the smart contract for the business network easily and efficiently. The smart contract in the hyper ledger-based business network consists of four major components; model for defining the participants, script for business logic, access control rule for permission or security and queries for accessing the ledger database. The participants run the business network and each participants have some assets and can perform transactions. The participants of our proposed system are suppliers, manufacturers, distributors, pharmacies, doctors, hospitals and patients. Particularly, the assets of our system are drug, raw material, orders, and record repository of system. On the other side, transactions of the system are defined during the development of smart contracts, how a user can interact with assets, performs transactions, events, participants involved in the private network, more specifically each and every activity is defined during smart contract development. The event functions are also parts of the transaction process function and execution procedure is similar to the transaction.
The hyper ledger fabric is developed based on distributed ledger technology which consists of two parts, a block chain part, and the world state part. Hyper ledger fabric can configure multiple world state databases to maintain the set of current values or states of the system for providing the functionality to access the current ledger states at any phase. The world state database part is capable to store the states of ledger efficiently and retrieves when application or user needed. Therefore, it can store the current state automatically and the developer of the system can check it easily without looking at the full log of transactions. The data are stored inside the world state database in the key-value pair.

\section{f. Result discussions}

The client application user interface is provided to each participant of the system where they can start their transaction after validating the identity. The client application communicates with the block chain network by using a REST server composer in which each request is sent through the REST server and will store the transaction in the block chain network. In the client web, application portal for drug management manufacture can add, update and delete the drug details in the block chain network. Afterward for adding new as well as available drug data manufacturer is given a web form to fill the entries and store the filled data in the block chain network. For adding drug, details in the block chain system using this web form that contains Drug ID, Name, company name, manufacture date, expiry date, and types are needed to fill. The manufacturer also shares the drug record data repository with the other participants like distributors, pharmacies, hospitals and doctors as well. The drug management portal will allow users to perform create, read, update, and delete operations with the help of the application user interface. The users can also update the information on the existing drug by sending the update request through the user interface to the block chain network. 
In[Ijazul Haq en. al. 2018],setup a secured and trusted network, where only the trusted parties are given permission to join the network and it have a userfriendly mobile APP that the participants will use to make transactions to the block chain.

In[ Kavita Kumari en. al. 2019],the framework can provide both manufacturer's authenticity as well as drug security and it is based on Block chain and is hence highly secure and capable of dealing with the fake drugs menace.

In[Faisal Jamil en., al. 2019],the network authorizes the user by validating the user ID, then the request will be initiated by the client to the REST server in order to submit the transaction to the proposed block chain platform.

\section{g. Comparison}

Table 1 presents a brief comparison of our system with the existing methodologies. It shows that our system performs better as compared to other existing works in the literature.

\section{Functionality}

\begin{tabular}{|l|l|l|l|l|l|}
\hline Work & $\begin{array}{l}\text { Smart } \\
\text { Contra } \\
\text { ct }\end{array}$ & $\begin{array}{l}\text { Cryp } \\
\text { to }\end{array}$ & $\begin{array}{l}\text { Netwo } \\
\text { rk } \\
\text { Type }\end{array}$ & $\begin{array}{l}\text { Efficien } \\
\text { cy }\end{array}$ & {$[6]$} \\
\hline $\begin{array}{l}\text { [Soundary } \\
\text { a,k } \\
\text { en., al. } \\
\text { 2018] }\end{array}$ & No & $\begin{array}{l}\text { Ye } \\
\text { s }\end{array}$ & $\begin{array}{l}\text { Permissi } \\
\text { oned }\end{array}$ & Low & $\begin{array}{l}\text { Drug } \\
\text { SCM }\end{array}$ \\
\hline $\begin{array}{l}\text { [Tseng, } \\
\text { J.H } \\
\text { en., al. } \\
\text { 2018] }\end{array}$ & Yes & $\begin{array}{l}\text { Ye } \\
\text { s }\end{array}$ & $\begin{array}{l}\text { Permissi } \\
\text { on less }\end{array}$ & Low & $\begin{array}{l}\text { Drug } \\
\text { SCM }\end{array}$ \\
\hline $\begin{array}{l}\text { [Guardtim } \\
\text { e, } \\
\text { 2020] }\end{array}$ & No & Ye & $\begin{array}{l}\text { Permissi } \\
\text { on less }\end{array}$ & Low & EMR \\
\hline
\end{tabular}

\begin{tabular}{|l|l|l|l|l|l|}
\hline Work & $\begin{array}{l}\text { Smart } \\
\text { Contra } \\
\text { ct }\end{array}$ & $\begin{array}{l}\text { Cryp } \\
\text { to }\end{array}$ & $\begin{array}{l}\text { Netwo } \\
\text { rk } \\
\text { Type }\end{array}$ & $\begin{array}{l}\text { Efficien } \\
\text { cy }\end{array}$ & {$[6]$} \\
\hline $\begin{array}{l}\text { [Prisco } \\
\text { en., al. } \\
\text { 2016] }\end{array}$ & Yes & $\begin{array}{l}\text { Ye } \\
\text { s }\end{array}$ & $\begin{array}{l}\text { Permissi } \\
\text { on less }\end{array}$ & High & EMR \\
\hline $\begin{array}{l}\text { [HealthCo } \\
\text { in, } \\
\text { 2020] }\end{array}$ & Yes & $\begin{array}{l}\text { Ye } \\
\text { s }\end{array}$ & $\begin{array}{l}\text { permissi } \\
\text { on less }\end{array}$ & Low & EMR \\
\hline $\begin{array}{l}\text { Proposed } \\
\text { SCM }\end{array}$ & No & $\begin{array}{l}\text { Ye } \\
\text { s }\end{array}$ & $\begin{array}{l}\text { Permissi } \\
\text { oned }\end{array}$ & High & $\begin{array}{l}\text { Drug } \\
\text { SCM }\end{array}$ \\
\hline
\end{tabular}

\section{CONCLUSION}

We found that block Chain approach was the best way to solve the problem of Counterfeit drugs, but no paper has implemented a drug recommendation system for the users. Other approaches of block chain which fails in providing a decentralised system, permissioned Block chain (private block chain) network as additional security. Most of the papers uses public block chain and centralised network system as the approach to overcome the counterfeit drugs problem but it doesn't provide additional privacy or secured supply chain management. Majority of papers uses block chain technology as it has changed the traditional supply chain method to a new robust, automated, secure, audible and transparent way. Because block chain technology ensures that, the entire supply chain process is foolproof and prevents fake drugs from entering the system completely. Detecting counterfeit drugs using RFID codes requires hardware components, which is expensive and does not provide accurate results and implementation, can be difficult and time consuming. As future work, we will increase the network size and implement it in real-time pharmaceutical companies to test the performance and validity of our system. 


\section{REFERENCES}

[1]. Kavita Kumari, Kavita Saini "Data Handling \& Drug Traceability: Blockchain Meets Healthcare To Combat Counterfeit Drugs". IJSTR 2020

[2]. Ijazul Haq and Olivier Muselemu Esuka Blockchain Technology in Pharmaceutical Industry to Prevent Counterfeit Drugs" International Journal of Computer Applications march 2018

[3]. Kavita Kumari Kavita Sain and Olivier "CFDD (CounterFeit Drug Detection) using Blockchain in the Pharmaceutical Industry" . IJERT Dec 2019

[4]. Ghodekar Prachi Shrikant, Pokharkar Pooja Machhindra, Pokharkar Monika Baban " Traceability and detection of counterfeit medicine supply chain through Blockchain " Journal Of Gujrat Research Society,Nov 2019

[5]. Faisal Jamil, Lei Hang, KyuHyung Kim and DoHyeun Kim "A Novel Medical Blockchain Model for Drug Supply Chain Integrity Management in a Smart Hospital". MDPI Electronics 2019, 8, 505, 2019

[6]. Ms.Kajal Bharat Adsul, Prof. S.P.Kosbatwar." A Novel approach for Traceability and detection of counterfeit medicines through Block chain" Easychair preprint ISSN 2516-2314,2019

[7]. Jinhua Ma, Shih-Ya Lin, Xin Chen, Hung-Min Sun,Yeh-Cheng Chen " A Blockchain-Based Application System for Product AntiCounterfeiting" by. IEEE Access,2020

[8]. Hoai Luan Pham, Thi Hong Tran, and Yasuhiko " Practical Anti-Counterfeit Medicine Management System Based on Blockchain Technology" by. IEEE,2019

[9]. Soundarya, K.; Pandey, P.; Dhanalakshmi, R. A Counterfeit Solution for Pharma Supply Chain. EAI Endorsed Trans. Cloud Syst. 2018, 3. [CrossRef]
[10]. Tseng, J.H.; Liao, Y.C.; Chong, B.; Liao, S.W. Governance on the drug supply chain via gcoin blockchain. Int. J. Environ. Res. Public Health 2018, 15, 1055. [CrossRef]

[11]. [Guardtime. Guardtime. Available online: https:/guardtime.com/blog/dutch-governmentdeploysguardtime-s-ksi-blockchain-forintegrity-assurance/ (accessed on 12 March 2020).

[12]. Prisco, G. The Blockchain for Healthcare: Gem Launches gem Health Network with Philips Blockchain Lab. Bitcoin Magazine, 26 April 2016.

[13]. HealthCoin. HealthCoin. Available online: https://www.f6s.com/healthcoin/ (accessed on 23 February 2020).

[14]. WHO. Growing Threat from Counterfeit Medicines. Available online: https://www.who.int/bulletin/volumes/88/4/10 020410/en/ (accessed on 12 February 2020)

[15]. [Roxanne, E.; Lisa, D.; George, P. Anticounterfeiting in the fashion and luxury sectors: Trends and strategies. In AntiCounterfeiting-A Global Guide, 2013.Available online: https://iccwbo.org/content/uploads/sites/3/2016 /11/WTR-Anti-counterfeiting-2015-A-GlobalGuide-featuring-BASCAP-IntermediariesReport.pdf (accessed on 1 January 2020).

[16]. Khan, P.W.; Byun, Y. A Blockchain-Based Secure Image Encryption Scheme for the Industrial Internet of Things. Entropy 2020, 22, 175. [CrossRef]

[17]. [HealthCoin. HealthCoin. Available online: https://www.f6s.com/healthcoin/ (accessed on 23 February 2020).

[18]. Hasan, H.; AlHadhrami, E.; AlDhaheri, A.; Salah, K.; Jayaraman, R. Smart contract-based approach for

[19]. efficient shipment management. Comput. Ind. Eng. 2019, 136, 149-159. [CrossRef] 
[20]. Caliper, H. Hyperledger Caliper Architecture.

Available online:

https://hyperledger.github.io/caliper/

docs/2_Architecture.html (accessed on 10

March 2019).

[21]. Hyperledger. Hyperledger Caliper. Available online:

https://www.hyperledger.org/projects/caliper/

(accessed on 5 January 2019).

\section{Cite this article as :}

Dr. Lokesh M R, Suhail Ahmed M N , Saifulla Khan, "Block Chain Based Supply Chain Management for Counterfeit Drugs in Pharmaceutical Industry", International Journal of Scientific Research in Computer Science, Engineering and Information Technology (IJSRCSEIT), ISSN : 2456-3307, Volume 7 Issue 1, pp. 100-108, January-February 2021. Available at

doi : https://doi.org/10.32628/CSEIT217122

Journal URL : http://ijsrcseit.com/CSEIT217122 